\title{
LATE HOLOCENE NATURAL AND HUMAN-INDUCED ENVIRONMENTAL CHANGE RECONSTRUCTED FROM PEAT RECORDS IN EASTERN CENTRAL CHINA
}

\begin{abstract}
Yan Zhao ${ }^{1,2} \bullet$ Adam Hölzer $^{3} \bullet$ Zicheng Yu ${ }^{1,4}$
ABSTRACT. We present a high-resolution multiproxy record (geochemistry, macrofossil, and pollen) from a peatland in the Dajiuhu Basin in eastern central China. The chronology of the $120-\mathrm{cm}$ peat profile was controlled by 6 accelerator mass spectrometry (AMS) ${ }^{14} \mathrm{C}$ dates on plant remains, including 2 post-bomb dates. The age model was based on linear interpolations of calibrated ages. Plant macrofossil results indicate a major transition around 3600 cal BP from Sphagnum section Subsecunda and Drepanocladus sp. to Sphagnum imbricatum dominance, followed by the disappearance of $S$. imbricatum at 700 cal BP. These changes suggest a general sequence of local environment changes from a wet fen, through a Sphagnum-dominated peatland, to a dry sedge-dominated marsh, which are also reflected by change in peat lithology and composition. The drying trend after $3600 \mathrm{cal} \mathrm{BP}$ is in general agreement with the speleothem isotope record from this region and other paleoclimate records from east China, indicating a weakening summer monsoon resulting from a decrease in summer insolation. The shift to a dry environment at $700 \mathrm{cal}$ BP might have been caused by human activities. Appearance of Cerealia pollen at 3600-3200 cal BP suggests the first introduction of crop farming in the region, while its absence at 3200-2000 cal BP could be attributed to abandonment of farmland. The increase of Ti and Si since $1300 \mathrm{cal}$ BP may be related to agricultural activity and landscape erosion. A 2-step increase in $\mathrm{Pb}$ concentration at 1600 and $600 \mathrm{cal} \mathrm{BP}$ suggests 2 phases of industrial pollution intensity.
\end{abstract}

\section{INTRODUCTION}

The East Asian summer monsoon plays an important role in the hydrologic cycle and energy budget in southeast China (An et al. 2000). At the orbital timescale, monsoon intensity follows the precession-driven change in seasonal insolation, resulting in maximum monsoon intensity in the early Holocene and a subsequent weakening trend (Kutzbach 1981; COHMAP members 1988). In particular, there has been a general dry trend since $\sim 4000 \mathrm{cal}$ BP due to a weakening summer monsoon (e.g. Hong et al. 2000; Junmei et al. 2006; Wang et al. 2005). In the middle and lower reaches of the Yangtze River, lake-level and pollen records show that the Holocene moisture optimum period occurred around 7000-4000 cal BP (An et al. 2000; He et al. 2004).

Peat deposits provide a readily available natural archive of past environmental change. Recently, many studies using peat cores as paleoenvironmental archives have been carried out in China (e.g. Hong et al. 2000; Xie et al. 2002; Xu et al. 2002; Zhou et al. 2002). Here, we present a high-resolution multiproxy record from the Dajiuhu Basin (DJH) covering the last $4700 \mathrm{yr}$. The objectives of our study were to use radiocarbon dates to establish peat chronology; to reconstruct the local vegetation and environmental change; to investigate peat accumulation and development; and to detect the environmental impact from human activities, using lithology, plant macrofossil, pollen, and geochemistry data.

\section{STUDY SITE}

The Dajiuhu Basin is situated in central China $\left(31^{\circ} 24^{\prime}-31^{\circ} 33^{\prime} \mathrm{N}, 109^{\circ} 56^{\prime}-110^{\circ} 11^{\prime} \mathrm{E}\right.$ ) (Figure 1), a region that is strongly influenced by the East Asian summer monsoon. The basin at $1700 \mathrm{~m}$ above

\footnotetext{
'MOE Key Laboratory of Western China's Environmental System, College of Earth and Environmental Sciences, Lanzhou University, Lanzhou 730000, China.

${ }^{2}$ Corresponding author. Email:yanzhao@lzu.edu.cn.

${ }^{3}$ National Natural History Museum, Karlsruhe, Erbprinzenstr 13, D76133 Karlsruhe, Germany.

${ }^{4}$ Department of Earth and Environmental Sciences, Lehigh University, 31 Williams Drive, Bethlehem, Pennsylvania 18015, USA.
} 
sea level (asl) is surrounded by mountains of up to $3053 \mathrm{~m}$ in elevation. The mean annual temperature is $7.4^{\circ} \mathrm{C}$ at Dajiuhu meterological station (at $1800 \mathrm{~m}$ asl), with a maximum monthly temperature of $17.1^{\circ} \mathrm{C}$ in July and a minimum of $-2.4^{\circ} \mathrm{C}$ in January (based on data from 1975-2001). Mean annual precipitation is $1528.4 \mathrm{~mm}$.

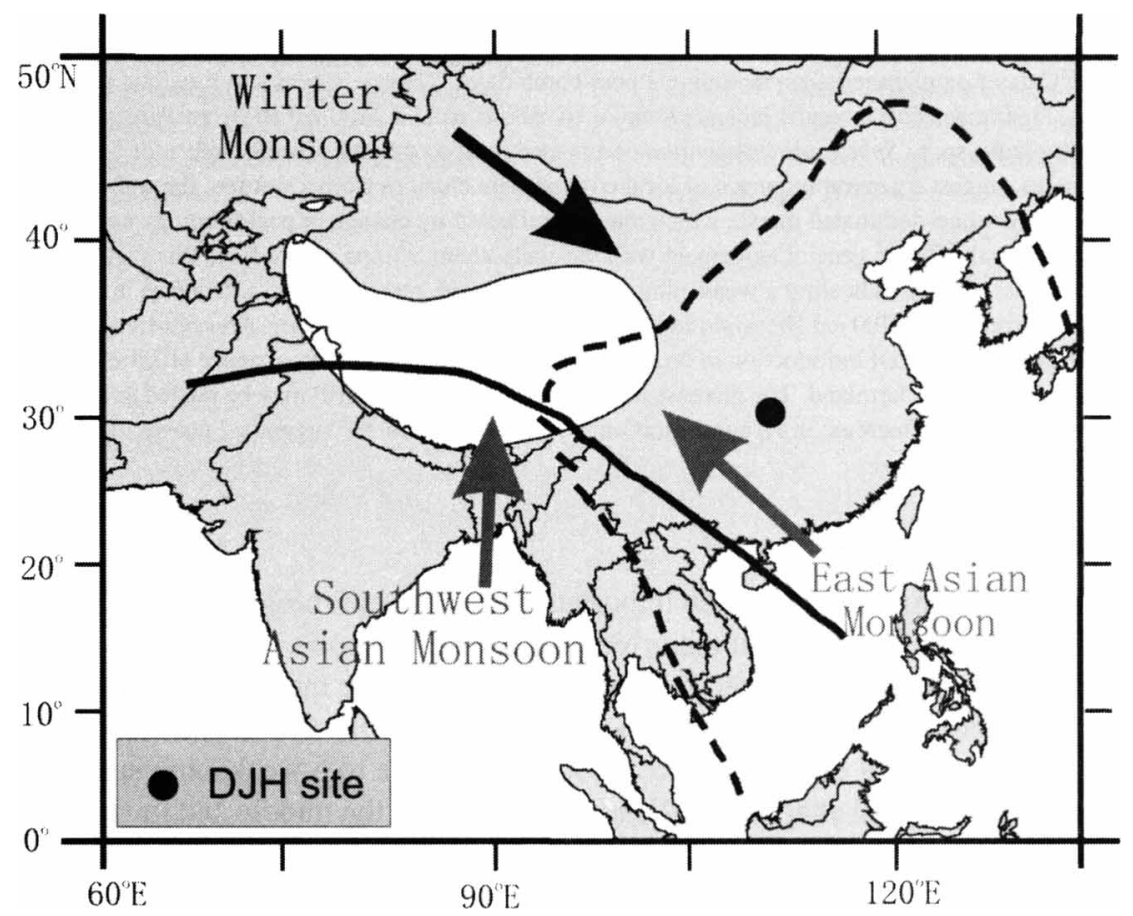

Figure 1 Location of the Dajiuhu Basin (black dot) in central China. The dashed line shows the present limit of the SE Asian summer monsoon influence, while the solid black line is the northern limit of the SW Indian monsoon.

The vegetation surrounding the basin is mainly composed of coniferous and deciduous broad-leaved forest. Above the elevation of $2000 \mathrm{~m}$, Pinus henryi, P. armandii, and Abies fargesii are dominant tree species. At the elevation of 1700-2000 m, the common trees are Quercus aliena, Q. variabilis, Q. acutissima, Castanea henryi, Fagus engleriana, F. lucida, Betula luminifera, Carpinus codata, Juglans regia, Pterocarya insigsis, Platycarya strobilacea, Rhus verniciflua, Rhus chinensis, Abies chinsiensis, Ilex chinensis, and Acer givaldii. The vegetation growing along the mountain slope facing the basin is mainly decidous broad-leaved forest dominated by Fagus ( $\mathrm{Li}$ and Yao 1993).

The Dajiuhu basin is about $16 \mathrm{~km}^{2}$ in area, with $62.5 \%$ of the area covered by marsh. There are several small inflowing streams that eventually disappear into an underground karst cave network, and the basin has no outlet. Within the basin, marsh is dominated by Carex sp., Sanquisorba officinalis, Juncus sp., and Gentiana pseudo-aquatica. Sphagnum sp. is only found in the center of the marsh. The soil pH is about 4.8-5.7 (Lang et al. 1983). 


\section{METHODS}

A peat profile ( $120 \mathrm{~cm}$ long) was taken in July 2000 in the southeast part of the marsh. The peat core was sliced into $1-\mathrm{cm}$ intervals and was stored at $4{ }^{\circ} \mathrm{C}$. Pollen, plant macrofossil, and geochemistry analyses were carried out at $2-\mathrm{cm}$ intervals.

Six samples of plant macrofossils were picked and dated using accelerator mass spectrometry (AMS) at Leibniz-Labor for Radiometric Dating and Stable Isotope Research (Kiel, Germany) and the AMS Dating Laboratory at Beijing University (Beijing, China) (Table 1). The plant macrofossils in the samples are mostly Sphagnum leaves or Cyperaceae leaves or stems, which would yield reliable ${ }^{14} \mathrm{C}$ dates (Nilsson 2001). All dates were calibrated to calendar years before present (AD 1950) using the program CALIB v 5.01 (Stuiver and Reimer 1993) with the IntCal04 data set (Reimer et al. 2004). Two post-bomb dates were calibrated with the CALIBomb program (http://calib.qub.ac. uk/CALIBomb/frameset.html). The age-depth model was based on linear interpolations of median calibrated ages. All discussion below is based on calibrated ages. In addition, the peat is acidic with a $\mathrm{pH}$ value of 4.8-5.7, so there is no dating or chronology problem related to peat acidity. The reliable chronology provides the basis of all discussions on the environmental change and human impact.

Table 1 AMS ${ }^{14} \mathrm{C}$ dates from a peat core in Dajiuhu Basin, central China.

\begin{tabular}{|c|c|c|c|c|c|c|}
\hline Lab nra & $\begin{array}{l}\text { Sample } \\
\text { depth } \\
(\mathrm{cm})\end{array}$ & $\begin{array}{l}\text { Material } \\
\text { dated }\end{array}$ & $\begin{array}{l}{ }^{13} \mathrm{C} \\
(\% \text { VPDB })\end{array}$ & $\begin{array}{l}{ }^{14} \mathrm{C} \text { date } \pm \\
\text { standard de- } \\
\text { viation }(\mathrm{BP})\end{array}$ & $\begin{array}{l}2-\sigma \text { range } \\
(\text { cal } B P)^{b}\end{array}$ & $\begin{array}{l}\text { Median age } \\
(\text { cal BP })^{\mathrm{b}}\end{array}$ \\
\hline KIA24683 & 4 & $\begin{array}{l}\text { Plant } \\
\text { remains }\end{array}$ & -28.4 & $\begin{array}{l}\text { Post-bomb } \\
\text { (119.8 pMC) }\end{array}$ & -33 to -35 & -34 \\
\hline KIA24680 & 12 & $\begin{array}{l}\text { Sphagnum } \\
\text { leaves }\end{array}$ & -25.1 & $\begin{array}{l}\text { Post-bomb } \\
\text { (119.4 pMC) }\end{array}$ & -9 to -11 & -10 \\
\hline LAMS05052 & 28 & $\begin{array}{l}\text { Sphagnum } \\
\text { leaves }\end{array}$ & -24.4 & $990 \pm 40$ & $795-964$ & 880 \\
\hline LAMS05051 & 54 & $\begin{array}{l}\text { Plant } \\
\text { remains }\end{array}$ & -26.1 & $1720 \pm 40$ & $1538-1713$ & 1626 \\
\hline KIA24681 & 74 & $\begin{array}{l}\text { Plant } \\
\text { remains }\end{array}$ & -22.8 & $3085 \pm 20$ & $3312-3360$ & 3336 \\
\hline KIA24682 & 118 & $\begin{array}{l}\text { Plant } \\
\text { remains }\end{array}$ & -26.6 & $4074 \pm 25$ & $4511-4625$ & 4568 \\
\hline
\end{tabular}

${ }^{a}$ KIA is Leibniz-Laboratory for Radiometric Dating and Stable Isotope Research (Kiel, Germany); LAMS is AMS Dating Lab at Beijing University (Beijing, China).

${ }^{\mathrm{b} C}$ Calibrated based on CALIB v 5.01 (Stuiver and Reimer 1993) using IntCal04 calibration data set (Reimer et al. 2004).

Two post-bomb samples were calibrated with the program CALIBomb (http://calib.qub.ac.uk/CALIBomb/ frameset.html).

Subsamples of $\sim 3 \mathrm{~g}$ were oven-dried at $105^{\circ} \mathrm{C}$ to estimate moisture content and then combusted at $550{ }^{\circ} \mathrm{C}$ for $12 \mathrm{hr}$ to estimate organic matter content (Dean 1974). The ash-free bulk density was calculated from the measurements of sample volume and organic matter. The peat accumulation rates were calculated by multiplying ash-free bulk density and vertical peat-growth rates, assuming constant vertical growth rates between pairs of dates in the age model.

Oven-dried samples were homogenized for elemental analysis. Subsamples ( 0.1 g) were used to determine nitrogen $(\mathrm{N})$ concentrations (Allen 1974). Milled subsamples $(\sim 0.2 \mathrm{~g})$ were used to determine lead $(\mathrm{Pb})$ by inverse voltammetry and phosphorus $(\mathrm{P})$ by flow-injection analysis (Allen 1974). 
Titanium ( $\mathrm{Ti}$ ) was determined by a continuous-flow photometric system with Tiron after $\sim 0.1$-g subsamples were ashed in a quartz crucible at $550{ }^{\circ} \mathrm{C}$. Another aliquot of $\sim 20 \mathrm{mg}$ was fused with sodium hydroxide for silicon ( $\mathrm{Si}$ ) determination by colorimetry using the molybdenum blue method (Allen 1974).

Pollen subsamples of $2 \mathrm{~g}$ were treated with a modified standard acetolysis method (Faegri and Iversen 1989), including $\mathrm{KOH}$ and acetolysis treatments. About 600 pollen grains were counted for each sample and were used as pollen sum for pollen percentage calculations. Subsamples $(\sim 1 \mathrm{~g})$ were used for plant macrofossil. Macrofossil percentages were based on all the macroremains counted. Unidentifiable debris represents mostly leaves, stems, and roots of Cyperaceae, along with fine debris.

\section{RESULTS}

The analyzed core covered the last $\sim 4700 \mathrm{yr}$ based on the age-depth model (Figure 2). It appeared that there was a shift from a constant deposition around $3.3 \mathrm{kyr}$, but unfortunately we have only 1 data point. However, this uncertainty would not change the general time sequence of the environmental change discussed below. Two post-bomb samples at $4 \mathrm{~cm}$ and $12 \mathrm{~cm}$ were calibrated to AD 1984 (-34 cal BP) and AD 1960 (-10 cal BP), respectively, based on their ${ }^{14} \mathrm{C}$ contents of 119.77 and $119.40 \mathrm{pMC}$ and their sequence in the peat core.
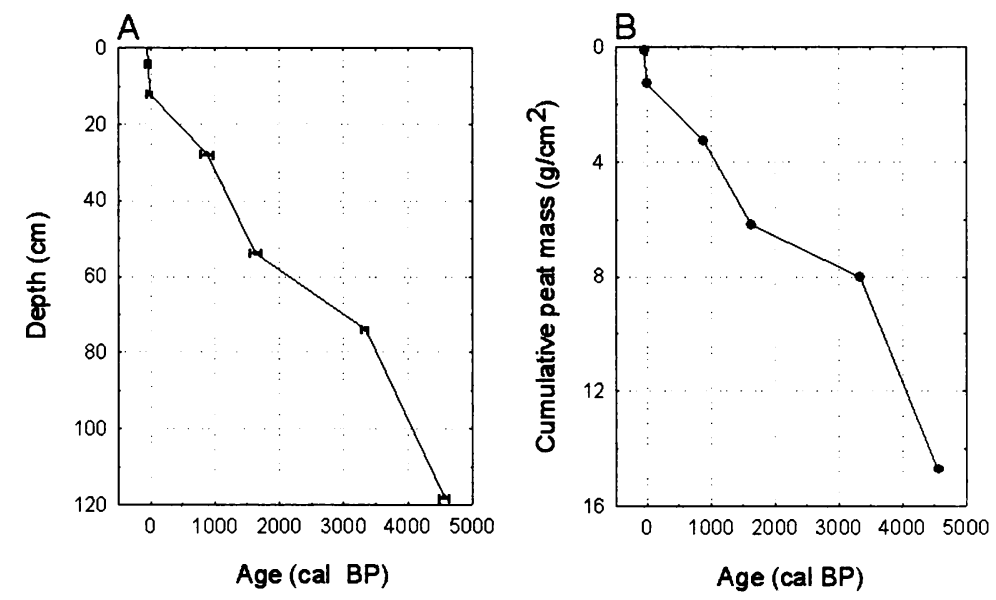

Figure 2 Age model and chronology. A) Age-depth model; B) Age-peat mass plot of the DJH peat profile at Dajiuhu Basin, eastern central China, based on median calibrated ages.

The water content of the peat core is $80-90 \%$ (Figure $3 \mathrm{~A}$ ) and organic matter is $\sim 80 \%$ of dry peat mass (Figure 3B). The ash-free bulk density varies mostly between 0.1 and $0.15 \mathrm{~g} / \mathrm{cm}^{3}$ (Figure $3 \mathrm{C}$ ). Increases in water content and organic matter at 3400 cal BP correspond with a sharp decrease in ash-free bulk density. Peat accumulation rate averages $115.3 \mathrm{~g} \mathrm{~m}^{-2} \mathrm{yr}^{-1}$, with the highest rate of $359 \mathrm{~g} \mathrm{~m}^{-2} \mathrm{yr}^{-1}$ after the 1960 s and the lowest rate of $11.9 \mathrm{~g} \mathrm{~m}^{-2} \mathrm{yr}^{-1}$ in $S$. imbricatum-dominated peat between 3300 and 2000 cal BP (Figure 3D). The age versus depth (measured as cumulative peat mass from the surface downward) curve shows curvature, but is inconclusive about whether this is a concave or convex pattern (Figure 2B). 


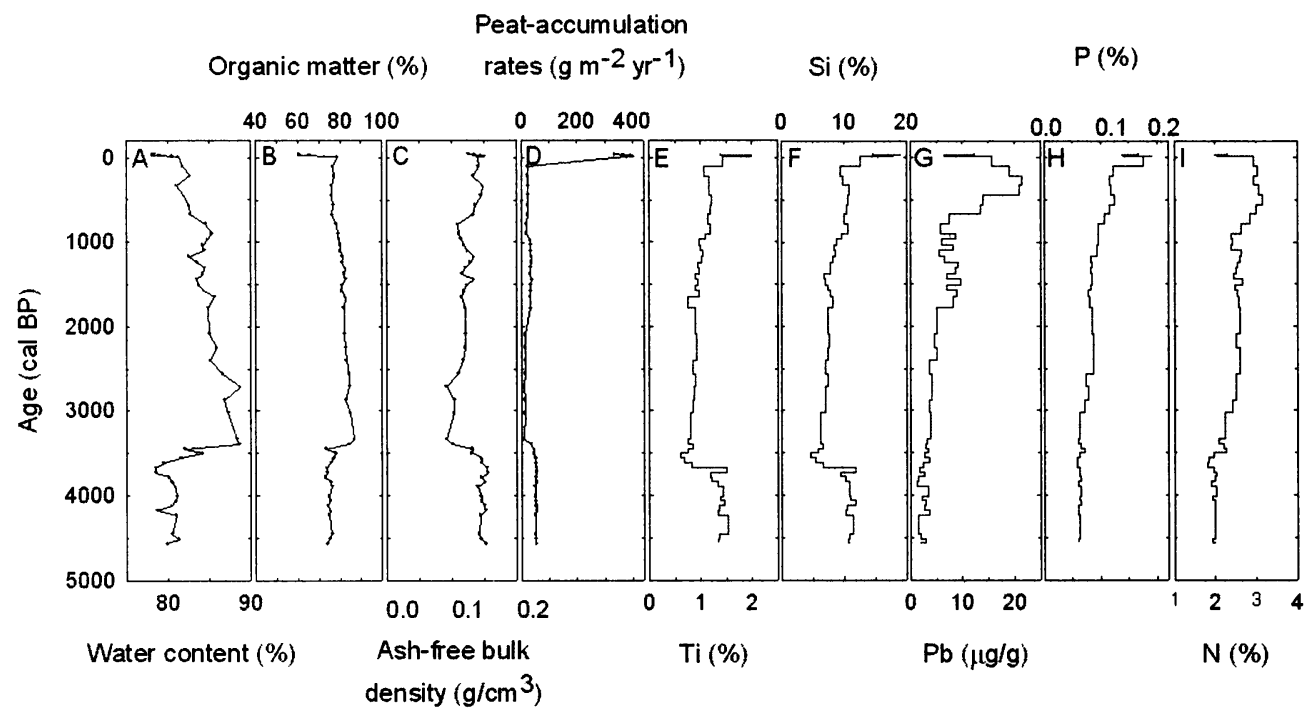

Figure 3 Peat composition and elemental concentrations: A) water content; B) organic matter content; C) ash-free bulk density; D) peat accumulation rates; E) titanium; F) silicon; G) lead; H) phosphorus; and I) nitrogen.

$\mathrm{Ti}$ and $\mathrm{Si}$ concentrations showed very similar changes over the past $4700 \mathrm{yr}$ (Figures 3E-F), with high values of $1.5 \% \mathrm{Ti}$ and $10 \% \mathrm{Si}$ at $4700-3400 \mathrm{cal} \mathrm{BP}$. A sharp decrease in both elements occurred at 3400 cal BP, followed by a gradual increase until the 1960 s, when both elements increased sharply to the highest concentrations. Pb showed a gradual increase from 3400 to $1500 \mathrm{cal} \mathrm{BP}$ and 2-step sharp increases at $1500 \mathrm{cal} \mathrm{BP}$ and at $700 \mathrm{cal} \mathrm{BP}$ (up to $22 \mu \mathrm{g} / \mathrm{g}$ ) (Figure 3G). Both P and N showed a gradual increase during the last $4700 \mathrm{yr}$ (Figures $3 \mathrm{H}$ and $3 \mathrm{I}$ ).

Macrofossil diagram was divided into 3 zones (Figure 4). Sphagnum imbricatum was the only Sphagnum species in Subzone 1a (4700-4200 cal BP), with some leaves of Drepanocladus sp. In Subzone 1b (4200-3600 cal BP), Sphagnum section Subsecunda appeared, at only <10\%. Zone 2 (3600-700 cal BP) was dominated by S. imbricatum (up to 95\%), while both Sphagnum section Subsecunda and Drepanocladus sp. disappeared. Sphagnum cf. balticum and S. cuspidatum were only found at 1 sample each in Subzone 2a. In Zone 3 (700 cal BP-present), S. imbricatum decreased sharply and disappeared. The Sphagnum-dominated peat had the lowest bulk density (Figure 3C).

Pollen results showed that over the last $4700 \mathrm{cal}$ BP, upland vegetation was dominated by Quercus (up to $38 \%$ ), Betula (up to 24\%), Fagus (up to 13\%), Corylus (up to 12\%), and Castanea (up to $11 \%$ ), while Cyperaceae dominated the local vegetation (up to 40\%). At 4700-3000 cal BP, Juniperus, Rumex, and Potamogeton was continuously present, and Polypodium was abundant (up to 6\%). Cerealia-type pollen appeared at 3600 cal BP, but almost disappeared at 3000-1200 cal BP (Figure 5).

\section{DISCUSSION}

\section{Peatland Development History During the Late Holocene}

Plant macrofossil results indicate a major transition around 3600 cal BP from Sphagnum section Subsecunda and Drepanocladus sp. to Sphagnum imbricatum dominance. S. imbricatum is a peat moss species that occurs over a wide range of water-table depths, while Sphagnum section Subse- 


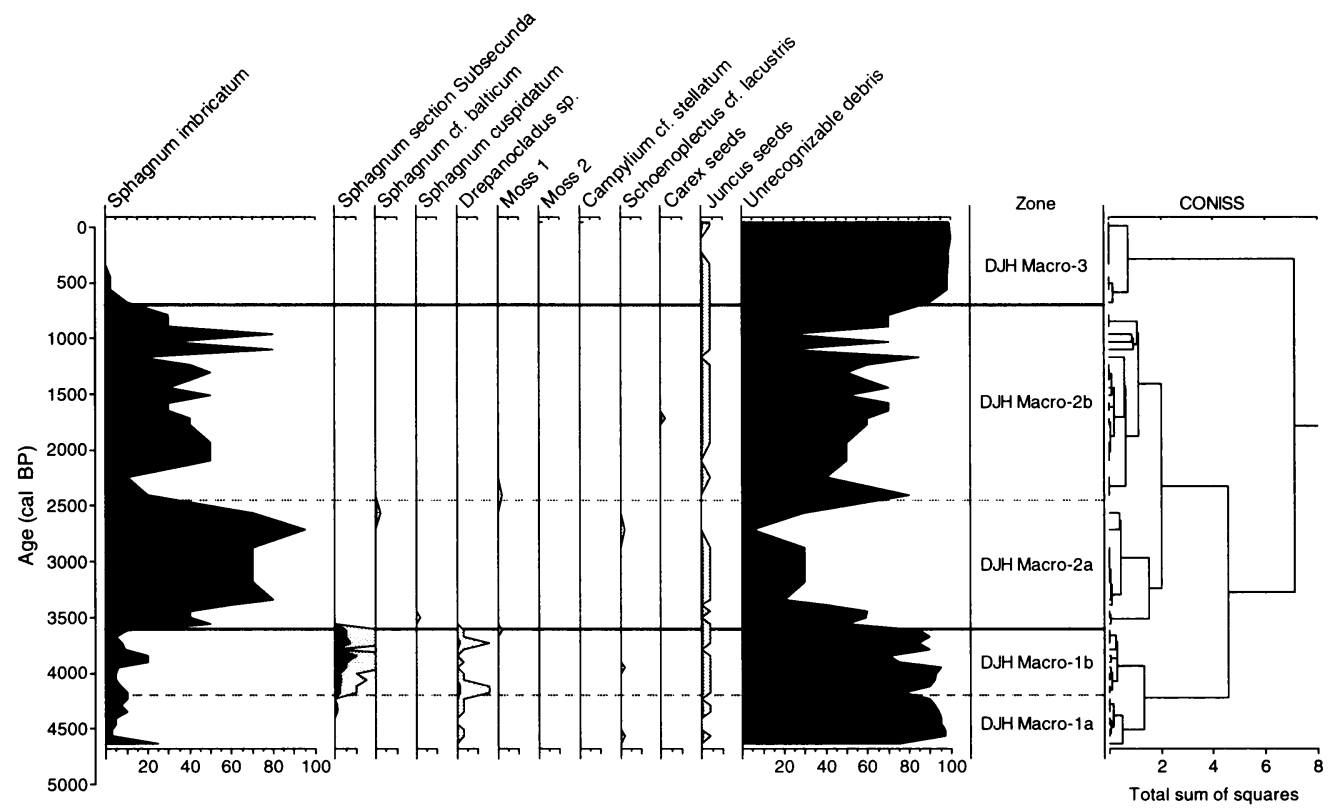

Figure 4 Percentage macrofossil diagram from the DJH peat profile at Dajiuhu Basin, eastern central China

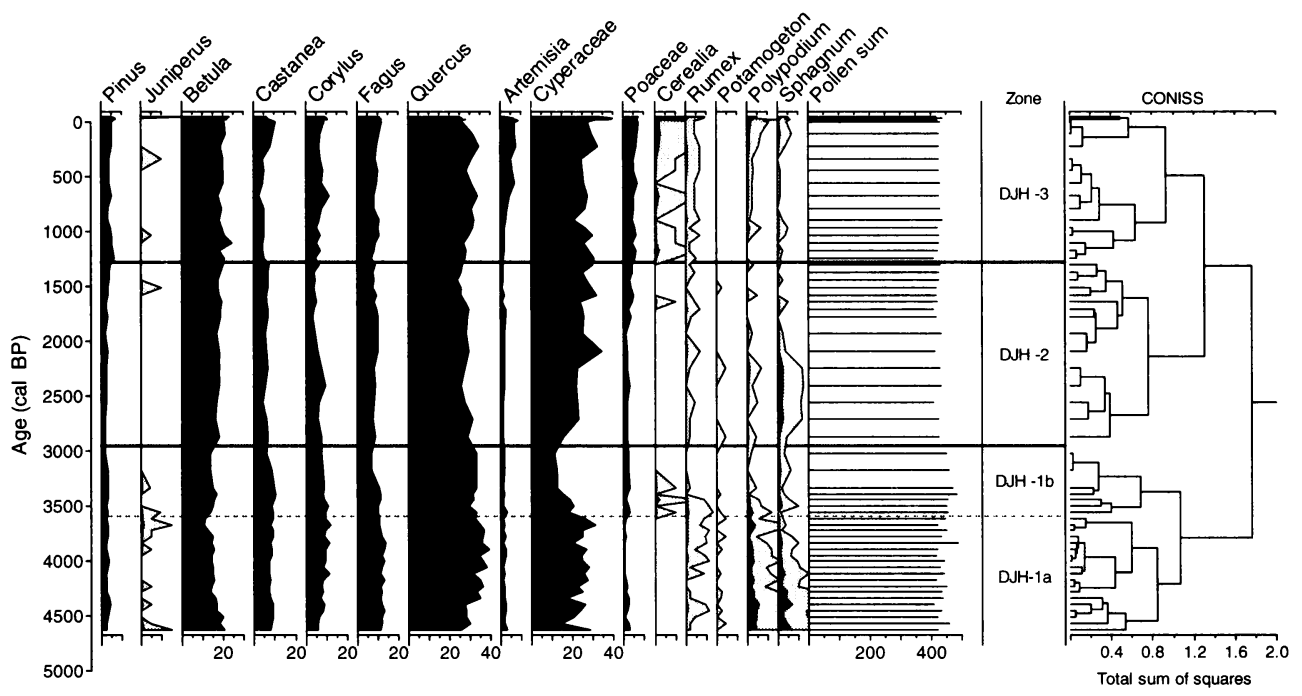

Figure 5 Percentage pollen diagram from the DJH peat profile at Dajiuhu Basin, eastern central China. Only selected taxa are shown.

cunda and brown moss Drepanocladus sp. prefer a wetter environment. Before 3600 cal BP, local vegetation comprised a rich (wet) fen, dominated by sedges, as indicated by abundant debris (likely from Cyperaceae), high Cyperaceae pollen, and some Drepanocladus sp. Between 3600 and $700 \mathrm{cal}$ BP, a bog or poor fen was indicated by dominant $S$. imbricatum. After 700 cal BP, a marsh environment with fluctuating water table is supported by the disappearance of all Sphagnum species and dominance of Cyperaceae. $S$. imbricatum has not been recorded in the modern flora of this area $(\mathrm{Li}$ 
and Si 1999). These vegetation changes suggest a general sequence of local environment changes from a wet fen, through a Sphagnum-dominated peatland, to a sedge-dominated marsh.

These major vegetation shifts are also reflected by changes in peat lithology and elemental composition. The wet minerotrophic fen period (4700-3600 cal BP) contains slightly lower organic matter and higher bulk density, suggesting input of inorganic material probably by streams. The elevated detrital input was also supported by high $\mathrm{Ti}$ and $\mathrm{Si}$ concentrations, which have been shown to be good indicators of soil erosion (Hölzer and Hölzer 1998). Ti rarely exists in plants, though Si can be found in plants such as Cyperaceae, Equisetum, or diatoms (Hölzer and Hölzer 1998). However, the strong correlation of $\mathrm{Ti}$ and $\mathrm{Si}$ in the DJH profile suggests that an increase in $\mathrm{Si}$ is likely caused by the erosion of mineral soils. High bulk density probably reflected elevated decomposition and compaction in this sedge-dominated minerotrophic fen. The gradual decrease in organic matter and increase in bulk density during the last $3400 \mathrm{yr}$ correspond with a decrease in $S$. imbricatum and an increase in unrecognizable debris (probably Cyperaceae).

Relatively high peat accumulation rates between 4700-3400 cal BP in the DJH profile were most likely caused by high bulk density and high vertical growth rate, in a nutrient-rich fen environment. The slight increase in peat accumulation after $\sim 2000 \mathrm{cal}$ BP might be related to the change from Sphagnum-dominated peatland to sedge-dominated marsh, along with increases in nutrient supplies, such as $P$ and $N$ (Figure 3 ). The highest accumulation rate during the last 40-50 yr was probably due to less decomposition of fresh litter and new peat in the acrotelm. Peat accumulation appeared to show neither a concave age-depth pattern nor a convex pattern due to the lack of dating resolution in DJH (Figure 2B).

\section{Impacts of Late Holocene Climate Change on Peatland Development}

The multiproxy data presented above (plant macrofossil, peat lithology, elemental composition) suggest a general drying trend during the late Holocene around the Dajiuhu Basin (Figure 6). The transition from a wet to a dry environment at 3600 cal BP was probably in response to the general weakening of the East Asian summer monsoon as predicted by the insolation hypothesis (Kutzbach 1981; COHMAP members 1988). This pattern has also been documented by other proxy records from this region and in east China. The speleothem isotope record from the nearby Shennongia region showed a general increase in oxygen isotope in the late Holocene due to the reduction in summer monsoon rainfall (Junmei et al. 2006). The $\delta^{18} \mathrm{O}$ record from the Jinchuan peat marsh from northeast China also suggests a decrease in monsoon rainfall from $\sim 3600$ cal BP (Hong et al. 2000). Zhang et al. (2004) reported a colder and drier climate after 3800 cal BP from a 6000-yr high-resolution speleothem isotope record from Xiangshui Cave in Guilin. A dry climate in the late Holocene has been characteristic of many regions influenced by the SE Asian summer monsoon in central and east China (An et al. 2000; He et al. 2004).

\section{History of Human Influences Derived from the Peat-Core Record}

Findings of Cerealia-type pollen between 3600-3200 cal BP comprise paleobotanical evidence for the first introduction of crop farming and agriculture in the region (Figure 6). This interpretation appears to be consistent with archaeological evidence indicating that the ancient civilizations in central China developed between the Yangtze and Yellow rivers from about 4500-3500 cal BP (Shi et al. 1993). This is the region where the Sanxingdui culture has been documented at the end of Neolithic period (Xiao 2002), including rice and Avena planting and wine brewing (Yang 1980). However, it is not known with certainty what had caused the disappearance of Cerealia pollen between 3200 and 2000 cal BP. Could climate change or social changes be the principle reason? In 


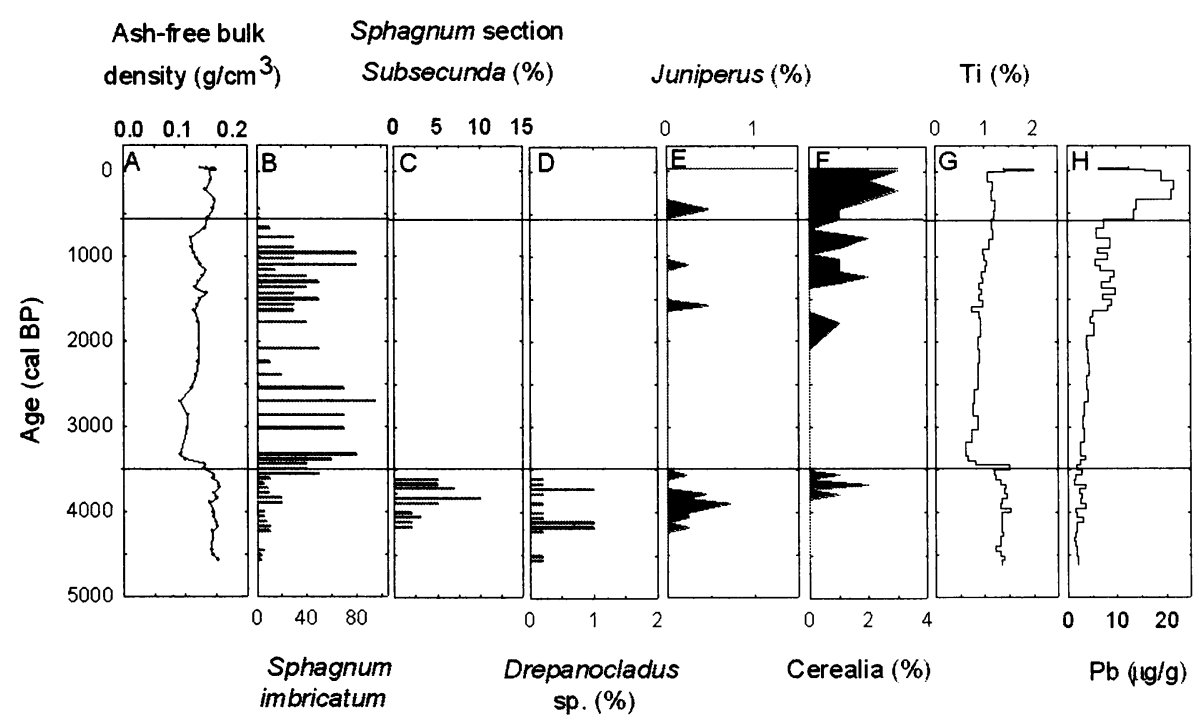

Figure 6 Multiproxy data from DJH peat core. A) Ash-free bulk density; B) Sphagnum imbricatum leaves; C) Sphagnum section Subsecunda leaves; D) Drepanocladus sp. leaves; E) Juniperus pollen, F) Cerealia pollen; $\mathrm{G}) \mathrm{Ti}$ concentration; and $\mathrm{H}$ ) $\mathrm{Pb}$ concentration.

the Shennongjia region, the Sanxingdui culture moved westward around 3700-3500 cal BP for unknown reasons. The disappearance of the Cerealia could have been due to population decline and the abandonment of agriculture in the wake of this population movement. However, this hypothesis needs to be further tested with additional records from this region. During the Qin and Han dynasties (starting from $\sim 2000$ cal BP), the population of the Shennongjia region started to increase again because of incoming people due to government exile and war refugees (Shennongjia Chorography Group 1996). The increasing abundance of Cerealia after 2000 cal BP corresponded with the general increase in human population, especially after $700 \mathrm{cal}$ BP when agriculture developed on a larger scale. The high Ti and Si concentrations in DJH profile after $1300 \mathrm{cal}$ BP correspond with a continuous occurrence of Cerealia pollen, suggesting landscape instability and soil erosion after forest clearance and agricultural activities (e.g. Hölzer and Hölzer 1998). The dry conditions after $700 \mathrm{cal}$ $\mathrm{BP}$, as indicated by the plant macrofossil results, might have been due to human activities through peat mining and altered drainage. It is interesting to note that Juniperus appeared to follow Cerealia pollen presence (Figure 6). We hypothesize that Juniperus shrubs might grow along the farmlands or villages, either planted or as a weed; however, there is no direct archaeological or other paleobotanical evidence to support this suggestion.

In the DJH profile, over the past $4700 \mathrm{cal}$ yr BP there were 2 phases of increase in $\mathrm{Pb}$ concentrations at $1600 \mathrm{cal} \mathrm{BP}$ and at $600 \mathrm{cal}$ BP (Figure 6), probably suggesting 2 stages in the intensity of industrial pollution. $\mathrm{Pb}$ became an important metal early in human history. Peat bogs have been used as archives of atmospheric metal deposition (e.g. Küster and Rehfuess 1997; Shotyk et al. 1998). The main source for the atmospheric lead could be from sulfide ores and metal smelting processes (Renberg et al. 2001). The increase at 1600 cal BP corresponded to the Han Dynasty, when ironing and advanced smelting techniques had developed. The second increase at $600 \mathrm{cal} \mathrm{BP}$ corresponded with the large scale steel and ironing during the Ming and Qing dynasties. Alternatively, some $\mathrm{Pb}$ could come from increased soil dust inputs resulting from deforestation and agriculture (e.g. Küster and Rehfuess 1997), while higher $\mathrm{Pb}$ concentration after 1600 cal BP could be derived from downward movement of younger peat that contains higher $\mathrm{Pb}$ concentration (Damman 1978). 


\section{CONCLUSIONS}

Plant macrofossil results indicated a major vegetation transition at 3600 cal BP in the Dajiuhu Basin in eastern central China, from Sphagnum section Subsecunda and Drepanocladus sp. to Sphagnum imbricatum dominance, followed by disappearance of $S$. imbricatum at $700 \mathrm{cal}$ BP. These changes suggest a general sequence of local environment changes from a sedge- and brown-moss-dominated rich fen, through a Sphagnum-dominated bog, to a dry sedge-dominated marsh.

The drying trend after 3600 cal BP was likely in response to the general weakening of the East Asian summer monsoon due to a decrease in summer insolation. This pattern is in general agreement with many records from east and central China.

Cerealia pollen at 3600-3200 cal BP is interpreted as evidence for the introduction of crop farming and agriculture in the region. The disappearance of Cerealia from 3200 to $2000 \mathrm{cal}$ BP might correspond to the emigration of the Sanxingdui culture and a decrease in population, as supported by archaeological records.

The high concentrations of Ti and Si after $1300 \mathrm{cal} \mathrm{BP}$ are correlated with continuous appearance of Cerealia pollen, suggesting elevated soil erosion following deforestation and agricultural activities. A 2-step increase in $\mathrm{Pb}$ concentration at 1600 and 600 cal BP suggests 2 more intense phases of industrial pollution in this region.

\section{ACKNOWLEDGMENTS}

This project was partly supported by the National Natural Science Foundation of China (NSFC Grant \#40301049), NSFC Innovation Team Project (\#40421101), and the K C Wong Fellowship from the German Research Exchange Centre (DAAD). The work was initiated while the senior author was a visiting scholar at National Natural History Museum, Karlsruhe, Germany. During the final preparation of the manuscript, the senior author was a visiting scholar at the Environmental Change Research Centre, University College London (UCL), supported by a joint fellowship between China Scholarship Council and UCL.

\section{REFERENCES}

Allen SE. 1974. Chemical Analysis of Ecological Materials. Oxford: Blackwell Scientific Publications. $565 \mathrm{p}$.

An ZS, Porter SC, Kutzbach JE, Wu XH, Wang SM, Liu XD, Li XQ, Zhou WJ. 2000. Asynchronous Holocene optimum of the East Asian monsoon. Quaternary Science Reviews 19(8):743-62.

COHMAP members. 1988. Climatic changes of the last 18,000 years: observations and model simulations. Science 241(4869): 1043-52.

Damman AWH. 1978. Distribution and movement of elements in ombrotrophic peat bogs. Oikos 30(3): 480-95.

Dean WE. 1974. Determination of carbonate and organic matter in calcareous sediments and sedimentary rocks by loss on ignition: comparison with other methods. Journal of Sedimentary Research 44(1):242-8

Faegri K, Iversen J. 1989. Textbook of Pollen Analysis. 4th edition. London: John Wiley and Sons. 338 p.

He Y, Theakstone WH, Zhang ZL, Zhang D, Yao TD,
Chen T, Shen YP, Pang HX. 2004. Asynchronous Holocene climate change across China. Quaternary Research 61(1):52-63.

Hölzer A, Hölzer A. 1998. Silicon and titanium in peat profiles as indicators of human impact. The Holocene 8(6):685-96.

Hong YT, Jiang HB, Liu TS, Zhou LP, Beer J, Li HD, Leng XT, Hong B, Qin XG. 2000. Response of climate to solar forcing recorded in a 6000 -year $\delta^{18} \mathrm{O}$ time-series of Chinese peat cellulose. The Holocene 10(1):17.

Junmei L, Zhang Q, Shiyan T, Jianhua J. 2006. The onset and advance of the Asian summer monsoon. Chinese Science Bulletin 51:80-8.

Küster H, Rehfuess K-E. 1997. Pb and Cd concentrations in a southern Bavarian bog profile and the history of vegetation as recorded by pollen analysis. Water, Air and Soil Pollution 100(3-4):379-86.

Kutzbach JE. 1981. Monsoon climate of the early Holocene: climate experiment with the Earth's orbital pa- 
rameters for 9000 years ago. Science 214(4516):5961.

Lang HQ, Jin SR, Zhu WC. 1983. Marsh in China. Shandong, China: Science and Technology Press. 25 p. In Chinese.

Li WY, Yao ZJ. 1993. Late Quaternary Vegetation and Environment of North and Middle Subtropical Region of China. Beijing: Ocean Press. p 27-47. In Chinese.

Li XJ, Si H. 1999. Sphagnaceae-Leucobryaceae. In: Gao C, He S, Crosby MR, editors. Moss Flora of China. Volume 1. St. Louis: Missouri Botanical Garden. $273 \mathrm{p}$.

Nilsson M, Klarqvist M, Bohlin E, Possnert G. 2001. Variation in ${ }^{14} \mathrm{C}$ age of macrofossils and different fractions of minute peat samples dated by AMS. The Holocene 11(5):579-86.

Reimer PJ, Baillie MGL, Bard E, Bayliss A, Beck JW, Bertrand CJH, Blackwell PG, Buck CE, Burr GS, Cutler KB, Damon PE, Edwards RL, Fairbanks RG, Friedrich M, Guilderson TP, Hogg AG, Hughen KA, Kromer B, McCormac G, Manning S, Bronk Ramsey C, Reimer RW, Remmele S, Southon JR, Stuiver M, Talamo S, Taylor FW, van der Plicht J, Weyhenmeyer CE. 2004. IntCal04 terrestrial radiocarbon age calibration, 0-26 cal kyr BP. Radiocarbon 46(3):1029-58.

Renberg I, Bindler R, Brännvall M-L. 2001. Using the historical atmospheric lead-deposition record as a chronological marker in sediment deposits in Europe. The Holocene 11(5):511-6.

Shennongjia Chorography Group. 1996. Chorography of Shennongjia. Wuhan, China: Hubei Science and Technology Press. p 1-79. In Chinese.

Shi YF, Kong ZC, Wang SM, Tang LY, Wang FB, Yao TD, Zhao XT, Zhang PY, Shi SH. 1993. Mid-Holocene climates and environments in China. Global and Planetary Change 7(1-3):219-33.

Shotyk W, Weiss D, Appleby PG, Cheburkin AK, Frei R, Gloor M, Kramers JD, Reese S, Van Der Knaap WO. 1998. History of atmospheric lead deposition since $12,370{ }^{14} \mathrm{C}$ yr BP from a peat bog, Jura Mountains, Switzerland. Science 281(5383):1635-40.

Wang FX, Qian NF, Zhang YL. 1995. Pollen Flora of China. Beijing: Science Press. 461 p. In Chinese.

Wang YJ, Cheng H, Edwards RL, He YQ, Kong XG, An ZS, Wu JY, Kelly MJ, Dykoski CA, Li XD. 2005. The Holocene Asian monsoon: links to solar changes and North Atlantic climate. Science 308(5723):854-7.

Xiao P. 2002. Gusu Civilization and Sanxingdui Culture. Chengdu, China: Sichuan People's Press. In Chinese.

Xie SC, Evershed RP. 2002. Peat molecular fossils recording paleoclimatic change and organic replacement. Chinese Science Bulletin 46:1749-52.

$\mathrm{Xu} \mathrm{H}$, Hong YT, Lin QH. 2002. Temperature variations in the past 6000 years inferred from $\delta^{18} \mathrm{O}$ of peat cellulose from Hongyuan, China. Chinese Science Bulletin 47:1181-6.

Yang XQ. 1980. The development of ancient culture in west Hubei and the formation of Chu culture. In: Proceedings of the 2nd Chinese Archaeology Annual Meeting. Beijing: Cultural Relics Publishing House. p 21-37. In Chinese.

Zhang M, Yuan D, Lin Y, Qin J, Bin L, Cheng H, Edwards RL. 2004. A 6000-year high-resolution climatic record from a stalagmite in Xiangshui Cave, Guilin, China. The Holocene 14(5):697-702.

Zhou WJ, Lu XF, Wu ZK. 2002. Peat record reflecting Holocene climatic change in the Zoige Plateau and AMS radiocarbon dating. Chinese Science Bulletin 47:66-70. 